\title{
Non-Secretory Myeloma or Light Chain-Producing Multiple Myeloma: A Case Report
}

\author{
Ana Rita Caldas, ${ }^{\mathrm{a}, \mathrm{b}}$, Mariana Brandao ${ }^{\mathrm{a}}$, Antonio Marinho ${ }^{\mathrm{a}}$
}

\begin{abstract}
Nonsecretory multiple myeloma (NSMM) is a rare variant of the classic form of MM that has a similar clinical and radiologic presentation except for the absence of the M-protein in serum and/or urine. Depending on the author, NSMM may have or not detectable monoclonal free light chain in urine/serum. We describe here a case of a 51-year-old woman who presented with back pain and multiple osteolytic bone lesions. This woman had no other symptoms and her serum basic analyses were normal. She had normal serum and urine protein electrophoresis, but a monoclonal kappa light chain band in plasmatic and urinary immunofixation was found. A CT guide biopsy from the D4 vertebra showed $9 \%$ plasmocytes in the bone marrow, $100 \%$ of them with an abnormal phenotype, all being CD38+ and CD138+, confirming the diagnosis of light chain myeloma, initially presenting as NSMM. A high index of suspicion is needed to diagnose cases like this, as the biology of NSMM is not completely understood. The potential value of more sensitive quantitative diagnostic techniques for this disease is being studied.
\end{abstract}

Keywords: Non-secretory myeloma; Monoclonal gammopathy; Immunoglobulin light chains; Free light chains

\section{Introduction}

Multiple myeloma (MM) is a neoplasia of plasma cells (PCs), hallmarked by tumor cell tropism for the bone marrow (BM) and production of monoclonal immunoglobulin

Manuscript accepted for publication March 1, 2011

${ }^{a}$ Medicine Department, Santo Antonio's Hospital, Largo Prof. Abel Salazar, 4099-001 Porto, Portugal

${ }^{b}$ Corresponding author: Ana Rita Caldas, E-mail: rita.pge@gmail.com

doi:10.4021/jmc156w
(Ig) detectable in serum and/or urine. Although MM is the 2nd most commonly diagnosed hematologic malignancy in the Western world, it is often viewed inaccurately as a rare disease because the short survival (compared to many other hematologic neoplasias) and because uniformly fatal outcome of patients markedly decreases the prevalence of MM in the population [1].

At present, it accounts for $2 \%$ of all cancer deaths and nearly $20 \%$ of deaths caused by hematological malignancies in the United States. The incidence is twofold higher in African Americans than in Caucasians, with a significantly higher incidence in males [2]. The roles of genetic background and environment are poorly defined, although there is evidence for some clustering within families $[1,2]$.

It is a slowly proliferating tumor, typically with less than $1 \%$ of tumor cells synthesizing DNA, until late in the disease, when multiple myeloma cells are often found outside the bone marrow. A pre-malignant lesion called monoclonal gammopathy of undetermined significance (MGUS), which is present in $1 \%$ of adults, progresses to malignant multiple myeloma and plasma cell leukemia at a rate of $1 \%$ per year [2].

Nonsecretory multiple myeloma (NSMM) is a rare variant of the classic form of MM, ranging from $1 \%$ to $5 \%$ of all cases of MM, and has a similar clinical and radiologic presentation except for the absence of monoclonal gammopathy. The first case of this variant was described in 1958 [3].

While some authors consider NSMM as an entity that secretes neither entire immunoglobulins nor immunoglobulin light chains $[3,4,5]$, others assume that all the ones that do not have the M-protein in electrophoresis can be classified as NSMM, in spite of having small elevations of monoclonal free light chains in serum and/or urine [6-9]. In the first case, plasmocytes fail to produce or secrete an immunoglobulin, so there is no any kind of monoclonal spike. In the second case there is lack of a detectable M-protein because the cell does not produce the entire immunoglobulin, but a monoclonal free light chain peak can be detected in serum or urine, using techniques other then agarose gel electrophoresis, like immunoelectrophoresis or immunofixation [7, 9].

With increasing sensitivity of detection of M-protein and the development of new techniques for detection of 


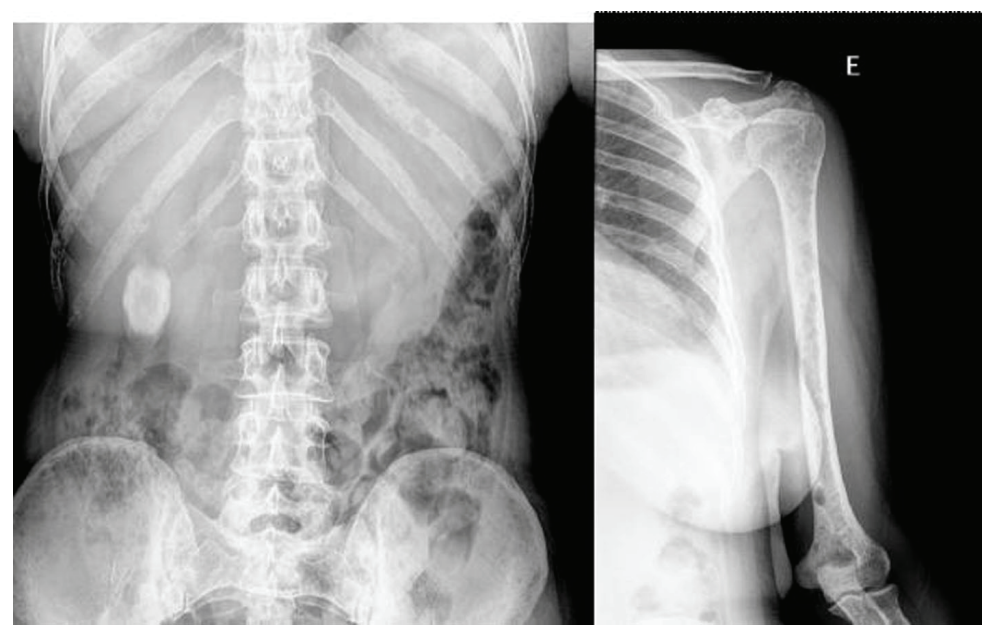

Figure 1. Skeleton X-ray showing multiple diffuse osteolytic lesions.

small amounts of free light chains in serum and urine, the diagnosis of true NSMM is decreasing [7].

We present here a case of NSMM with detectable free light chains in serum and urine but without the M-protein spike, clinically presenting as multiple sintomatic osteolytic lesions.

\section{Case Report}

A 51-year-old Caucasian woman was admitted to our hospi- tal because of multiple diffuse osteolytic lesions in the vertebral column. The patient had a 10-month history of back pain without history of trauma and with no improvement using anti-inflammatory therapy. Seven months after the beginning of the pain, a computerized tomography (CT) scan of the vertebral column showed diffuse osteolytic lesions in C6-C7, C7-D1 and a larger one in L5, with rupture of the bone cortical layer. One month later a magnetic resonance imaging (MRI) of the spine and vertebral column showed similar findings in C6, D1, D4, D7, D11 and L5. She was then admitted to our hospital for additional studies.

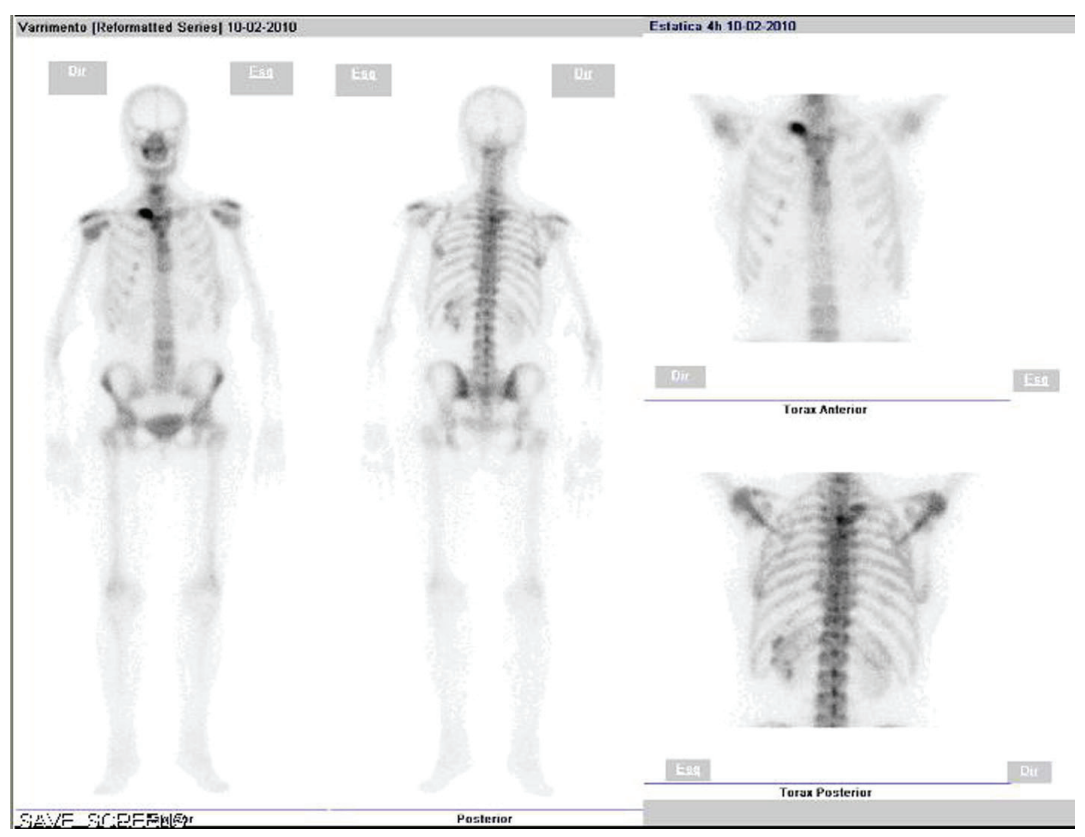

Figure 2. Skeleton bone scan showing increased uptake in the right clavicle, third right rib and D4, without any further uptake. 


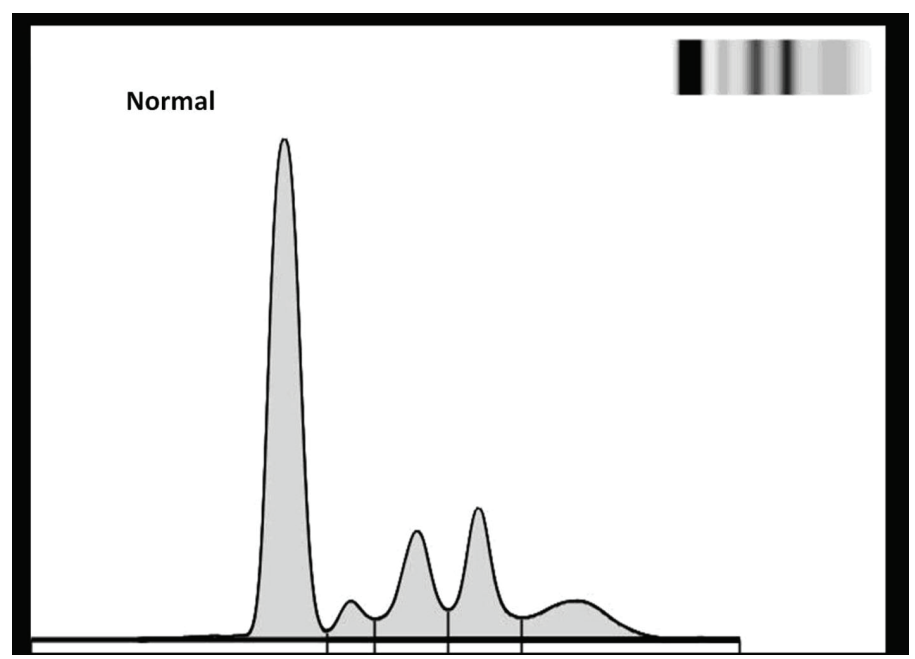

Figure 3. Serum electrophoresis (agarose gel).

She was diagnosed two years ago with arterial hypertension and type 2 diabetes mellitus, and she was under medication for both. She had no other relevant facts on her medical records, or any known relevant familiar disease.

Her physical exam was completely normal, with no neurologic deficits. Laboratory values were the following: hemoglobin $13 \mathrm{~g} / \mathrm{dL}$, hematocrit 39\%, BUN $18 \mathrm{mg} / \mathrm{dL}$, creatinine $0.52 \mathrm{mg} / \mathrm{dL}$, calcium $2.27 \mathrm{mmol} / \mathrm{L}$, phosphate $1.07 \mathrm{mmol} / \mathrm{L}$, total protein $6 \mathrm{~g} / \mathrm{dL}$, albumin $3.96 \mathrm{~g} / \mathrm{dL}, \beta 2$ microglobulin $2,019 \mathrm{ng} / \mathrm{mL}$, parathyroid hormone $31.2 \mathrm{pg} /$ $\mathrm{mL}$, bone alkaline phosphatase $22 \mathrm{U} / \mathrm{L}$ and $\mathrm{D}$ vitamin 19.08 $\mathrm{nmol} / \mathrm{L}$. All of these values were normal except for D vitamin, whose levels were low.

Skeleton X-ray showed multiple diffuse osteolytic lesions, particularly in long bones and ribs (Fig. 1). Thoracoabdomino-pelvic CT scan showed no findings beside those of the skeleton, with no evidence of any primary or other secondary neoplasic lesions. A subsequent skeleton bone scan showed small areas of increased uptake in the right clavicle, right third rib and D4, without any further uptake (Fig. 2). We excluded all the neoplasms expected for this age. We have done mammography, mammary ultrassonography, upper endoscopy, colonoscopy, pelvic ultrassonography and cervical smear; all of these were normal.

Serum protein electrophoresis was normal (no spike detectable) (Fig. 3). The levels of the immunoglobulin were IgG $771 \mathrm{mg} / \mathrm{dL}$ (normal $793-1590 \mathrm{mg} / \mathrm{dL}$ ), IgA $56.8 \mathrm{mg} /$ dL (normal $114-457 \mathrm{mg} / \mathrm{dL}$ ), IgM $39.3 \mathrm{mg} / \mathrm{dL}$ (normal 29 - $226 \mathrm{mg} / \mathrm{dL}$ ), $\operatorname{IgD}<1$ (normal $<4 \mathrm{mg} / \mathrm{dL}$ ), which is lower than normal for IgA and IgG. The level of serum free kappa light chains was $96.8 \mathrm{mg} / \mathrm{dL}$ (normal $0.33-1.94 \mathrm{mg} / \mathrm{dL}$ ); serum free kappa/lambda ratio was $123.85 \mathrm{mg} / \mathrm{dL}$ (normal 0.26 - $1.65 \mathrm{mg} / \mathrm{dL}$ ). Despite of the normal appearance of serum electrophoresis, serum immunofixation showed a monoclonal gammopathy of free kappa light chains. A 24-hour urine specimen showed no proteinuria (193 mg in 24 hours). Urine electrophoresis was normal (no spike detectable). Immunoglobulin concentrations in urine were normal, as were the concentrations of kappa and lambda light chains. Urine immunofixation showed a monoclonal band corresponding to the elimination of free kappa light chains.

A CT guide biopsy from the D4 vertebra showed 9\% plasmocytes in the bone marrow, $100 \%$ of them with an abnormal phenotype, all being CD38+ and CD138+, confirming the diagnosis of light chain myeloma, initially presenting as NSMM.

After confirmation of the diagnosis, our patient was proposed to start treatment with 3 to 6 cycles of bortezomib and dexametason, followed by autologous stem cell transplantation.

\section{Discussion}

Nonsecretory multiple myeloma (NSMM) is a rare variant of the classic form of MM that has a similar clinical and radiologic presentation except for the absence of the M-protein in serum and/or urine. Depending on the author, NSMM may have or not detectable monoclonal free light chain in urine/ serum.

In this particular case, our patient presented with osteolytic bone lesions associated with pain, with no other symptoms or alteration on serum basic analysis, including normal serum protein electrophoresis (agarose gel) and negative tumoral markers. The diagnosis of multiple myeloma relied on the result of the bone marrow biopsy, which showed a predominant population of atypical plasmocytes, and the absence of uptake on the bone scan. With further studies we found plasmatic elevation of free kappa light chains and a monoclonal kappa free light chain band in plasmatic and uri- 
nary immunofixation, but there was no M-protein in urinary or plasmatic electrophoresis with agarose gel. This led us to classify this myeloma as non-secretory.

On the other hand, it's important to have in mind that this diagnosis was probably made early in the course of the disease: absence of blood tests alterations, no clinical manifestations other than bone pain and a low percentage of plasmocytes in the bone marrow (comparing with the $10 \%$ minimum required to classify it as a MM). It's possible that if the diagnosis was made later in the course of the disease, we had different test results and the diagnosis could have been made easily.

There are studies showing that a cytoplasmic M-protein can be identified by immunohistochemistry in nearly $85 \%$ of these patients initially classified as NSMM: with increasing sensitivity of detection of M-protein, the diagnosis of true NSMM is decreasing $[4,7]$. This is especially true with the introduction of immunoglobulin free light chain assays that are capable of detecting small elevations in monoclonal free light chains, which would otherwise have escaped detection by agarose gel electrophoresis and immunoelectrophoresis $[4,7,10]$. It's possible that this is what happened in this particular case. Initially, we detected no M-protein in serum or urine; agarose gel electrophoresis was normal. We only found a monoclonal gammopathy of kappa light chains in serum and urine with immunofixation techniques. It is possible that by using more sensitive techniques we would have detected an M-protein spike earlier, diagnosing the disease earlier.

With cases like this we conclude that in patients with signs, symptoms and radiologic findings (including bone scan) typical of MM but with no M-protein in plasmatic and/ or urine electrophoresis, the hypothesis of NSMM should always be considered. Besides marrow aspiration and biopsy, more advanced techniques like immunoelectrophoresis or immunofixation may be necessary to confirm the diagnosis [9]. The quantification of free light chains in serum is probably also useful for the diagnosis and monitoring of many patients with nonsecretory myeloma [7]. Observation of the affected cells by electron microscopy may also be useful for the identification of cell lineage and more accurate diagnosis of NSMM, identifying well-developed rough endoplasmic reticulum, a clear Golgi apparatus and cytoplasmic phagocytic vacuoles [8].

The treatment of secretory and non-secretory MM is similar, and the prognosis is also identical $[3,4,10,11]$.

The detection of a small quantity of serum paraprotein in a case of NSMM raises important questions about the biology of this disease and highlights the potential value of more sensitive techniques as a diagnostic aid. With the development of these quantitative methods, it's possible that the biochemical monitoring of the disease and the response to treatment will become easier. Further studies are now necessary to better understand the etiology, pathogenesis and evolution of this disorder, since its adequate treatment relies on the full understanding of its pathologic mechanisms.

\section{Disclosure Statement}

We declare we do not have any conflicts of interest. We had no grant support or other kind of assistance.

\section{References}

1. Mitsiades CS, Mitsiades N, Munshi NC, Anderson KC. Focus on multiple myeloma. Cancer Cell 2004;6(5):439444.

2. Kuehl WM, Bergsagel PL. Multiple myeloma: evolving genetic events and host interactions. Nat Rev Cancer 2002;2(3):175-187.

3. Abdalla IA, Tabbara IA. Nonsecretory multiple myeloma. South Med J 2002;95(7):761-764.

4. Kumar S, Perez WS, Zhang MJ, Ballen K, Bashey A, To LB, Bredeson CN, et al. Comparable outcomes in nonsecretory and secretory multiple myeloma after autologous stem cell transplantation. Biol Blood Marrow Transplant 2008;14(10):1134-1140.

5. Kyle RA. Multiple myeloma: review of 869 cases. Mayo Clin Proc 1975;50(1):29-40.

6. Rubio-Felix D, Giralt M, Giraldo MP, Martinez-Penuela JM, Oyarzabal F, Sala F, Raichs A. Nonsecretory multiple myeloma. Cancer 1987;59(10):1847-1852.

7. Drayson M, Tang LX, Drew R, Mead GP, Carr-Smith H, Bradwell AR. Serum free light-chain measurements for identifying and monitoring patients with nonsecretory multiple myeloma. Blood 2001;97(9):2900-2902.

8. Kuyama J, Kosugi S, Take H, Matsuyama T, Kanayama Y. Non-secretory multiple myeloma with azurophilic granules and vacuoles: an immunological and ultrastructural study. Intern Med 2004;43(7):590-594.

9. Sheehan T, Sinclair D, Tansey P, O'Donnell JR. Demonstration of serum monoclonal immunoglobulin in a case of non-secretory myeloma by immunoisoelectric focusing. J Clin Pathol 1985;38(7):806-809.

10. Bourantas K. Nonsecretory multiple myeloma. Eur J Haematol 1996;56(1-2):109-111.

11. Smith DB, Harris M, Gowland E, Chang J, Scarffe JH. Non-secretory multiple myeloma: a report of 13 cases with a review of the literature. Hematol Oncol 1986;4(4):307-313. 